\title{
Extended input-output model for urbanization: an empirical test using Chinese data
}

\author{
Nobuhiro Okamoto ${ }^{*}$ [D
}

\author{
${ }^{*}$ Correspondence: \\ okamoton@ic.daito.ac.jp \\ Daito Bunka University, \\ 560 Iwadono, \\ Higashimatsuyama-shi, \\ Saitama 355-8501, Japan
}

\begin{abstract}
Although the input-output model has been widely used for both pure economic analysis and environmental issues, demographic analysis has been relegated to the periphery of the input-output literature. Previous researchers have made significant contributions in developing the economic-demographic modeling from the unemployment perspective, in the context of shrinking regional economies. This study aims to develop an extended input-output model for urbanization, based on the Batey-Madden model by incorporating the "urbanization process". This process is associated with one of the facets of demographic change and has received little attention in the literature. The effectiveness of the model is theoretically explored and empirically tested using Chinese data, which show rapid progress of urbanization in China. The study proposes a new "urbanization multiplier", which implies intense population concentration in cities based on an employment multiplier in urban areas and labor allocation possibilities between urban and rural areas. The result from a preliminary application shows that the economic structure can determine the urbanization multiplier, indicating that the extent of employment opportunities promotes urbanization and the size of the population attracts more workers from rural areas. The model provides a fresh aspect of urbanization in the existing literature.
\end{abstract}

Keywords: Demography, Urbanization, Migration, Input-output analysis

\section{Introduction}

Demography is a crucial factor for the sustainable economic development of any region. It is widely known that demographic change affects economic growth and that economic development influences family planning, leading to a change of demography in a society. Demographic change includes a wide variety of phenomena, including change in labor participation, such as employment and unemployment; subsequent shift in population age structure, which means an expanding or shrinking volume of working-age group; decline or rise in fertility; and life expectancy. Thus, it is clear that demography matters a great deal for economic growth.

Input-output analysis has been widely applied to regional economic issues, such as identification of leading industries, impact of new industry establishment, and 
employment and unemployment (see Miller and Blair 2009), since it can provide a comprehensive picture of the whole industrial economy in terms of both demand (including consumption and capital formation) and supply (including compensation for workers and created value added). There is no doubt that the most important issue for regional economies is the existence of unemployment, employment, and household consumption. However, conventional input-output analysis has paid only limited attention to changes in output by industrial activities; furthermore, the framework excludes households, not to mention population and labor force. A body of work by Batey and co-researchers, particularly in the 1980s, has positively contributed to the field of the extended input-output model for demography, especially employment and unemployment in labor accounts (Batey and Madden 1981, 1988, 1999a, 1999b; Batey 1985; Batey and Weeks 1987, 1989; Batey et al. 1987). The development and potential of this model has been discussed by Batey and Rose (1990); more recently, the model has been reviewed in the context of declining regional economies (Batey 2018).

The Batey-Madden model has four components: the economic (inter-industry) interaction submatrix, the demographic interaction submatrix, the demographic-economic interaction submatrix, and the economic-demographic interaction submatrix. Since the abovementioned works focus on the employment problem and the consumption associated with unemployment, the model interpretation has mainly focused on the demographic-economic interaction (or the impact of change in employment levels on consumption), and the economic-demographic interaction (or the impact of changes in production on employment). We find that there is relatively little investigation of the demographic interaction. Moreover, despite the significant academic contributions to the development of a consistent methodology for analyzing the economic-demographic relationship in the input-output framework, there have been few applications in this field. Considering the importance of demographic impact on the economy, this model has strong potential for further analysis of regional economic issues related to demography.

Urbanization is a kind of substantial geographical change that involves massive labor movement from rural to urban areas. Certainly, urbanization has also been given extensive attention in the input-output literature in the context of environmental impact (e.g., Ala-Mantila et al. 2014; Li et al. 2015; Feng and Hubacek 2016). However, urbanization itself has been treated as an exogenous factor in this literature, and the direct relationship or interdependency between urbanization and economy has been ignored.

This study aims to develop an extended input-output model for urbanization based on the Batey-Madden model by incorporating the "urbanization process". This process is associated with one of the facets of demographic change and has received little attention in the literature. The effectiveness of the model is theoretically explored and empirically tested using Chinese data, which show rapid progress of urbanization in China.

The paper consists of the following parts. Section 2 describes the extended model of demography that Batey and others focused on in their works. Then, we develop an input-output model for urbanization by applying the Batey-Madden model, and further discuss its multipliers. In Sect. 3, we present the empirical results of the Chinese urbanization process and explain how the model works. Finally, Sect. 4 discusses the results and concludes. 


\section{Input-output model for urbanization}

\subsection{Model for demography}

Based on a simple and very typical input-output model, final demand promotes an increase in the output of each sector via input-output relations among sectors. Thus, the final demand sectors, such as household consumption, government investment, and shipment in foreign trade, are considered as an exogenous sector. However, households, governments, and foreign economic entities are composed of important elements of domestic economic activity within the real world. In particular, categorizing households as the exogenous sector places a strain on the basic economic theory.

Households can earn income from the payment for their labor input to production processes; moreover, as consumers, they spend their income in well-patterned ways. In particular, a change in the amount of labor required for production in one or more sectors can lead to changes in the amount of spending by households as a group for consumption. On the grounds that households play an important role in the whole economy, some researchers, such as Miernyk et al. (1967) and Miyazawa (1976), have attempted to incorporate households into the input-output framework. ${ }^{1}$

In contrast to the input-output model for households, that for demography, which Madden and Batey (1980), Batey and Madden (1981) and Batey (1985) developed, has one unique feature: the variables of demography are measured as a number of people rather than as a monetary unit, which can capture changes in economic activities induced by changes in the amount of labor or demographic changes. These researchers proposed that the household activity variables, including both labor input and consumption expenditure, should be converted to units of population so that the model can be used to analyze demographic changes. By making various modifications to the conventional equation of input-output relations, they constructed an extended input-output model for demography (Batey 2018).

Using Eq. (1), we can describe the model in its most rudimentary form (Batey and Weeks 1987; Batey 2018). ${ }^{2}$ This is the so-called Batey-Madden model (Batey 2018): ${ }^{3}$

$$
\left[\begin{array}{ccc}
I-A & -\dot{h}_{c}^{\mathrm{em}} & -\dot{h}_{c}^{\mathrm{ue}} \\
-l & 1 & 0 \\
0 & 1 & 1
\end{array}\right]\left[\begin{array}{c}
x_{I} \\
e \\
u
\end{array}\right]=\left[\begin{array}{c}
d_{I} \\
0 \\
p
\end{array}\right]
$$

where $\dot{h}_{c}^{\mathrm{em}}$ is a column vector of consumption coefficients, expressed as consumption per person, for employed workers; $\dot{h}_{c}^{\text {ue }}$, a column vector of consumption coefficients, expressed as consumption per person, for unemployed workers; $l$, is a row vector of employment-production (employment/gross output ratios) functions by industrial

\footnotetext{
${ }^{1}$ The conventional input-output model is called an open model while this model is referred to as a closed model. The latter moves the household sector from the final demand items and value-added items to the open model as an endogenous sector and makes it one of the endogenous sectors, leading to the closure of the model for households. See Miller and Blair $(2009,34-41)$ for more details.

2 The earlier version of Madden and Batey's (1980) model was criticized for inconsistent consideration of employed and unemployed immigrants, and the associated changes in the size and structure of households (Hynes and Jackson 1988). This problem can be avoided by using a rudimentary form of the model, which was termed the "personal consumption framework" (Madden 1988)

${ }^{3}$ See Okamoto (2019a) for more details about the Batey-Madden model.
} 
Table 1 System of input-output model for demography

\begin{tabular}{lll}
\hline & Economic activities & Demographic activities \\
\hline Economic inputs & {$[I-A]$} & {$\left[\begin{array}{c}-\dot{h}_{c}^{\text {em }}-\dot{h}_{c}^{\text {ue }} \\
\text { Household consumption }\end{array}\right.$} \\
Demographic inputs & {$\left[\begin{array}{c}-l \\
0\end{array}\right]$} & {$\left[\begin{array}{ll}1 & 0 \\
1 & 1\end{array}\right]$} \\
& Household income & Household formation, \\
& generation of labor \\
& supply \\
\hline
\end{tabular}

sector; em, a scalar, the number of employed workers; ue, a scalar, the number of unemployed workers, and $p$ is a scalar, the level of labor supply.

The model consists of three blocks of simultaneous equations. The first block of equations establishes that the gross output is equal to the sum of intermediate and final demand:

$$
(I-A) x_{I}-\dot{h}_{c}^{\mathrm{em}} \mathrm{em}-\dot{h}_{c}^{\mathrm{ue}} \mathrm{ue}=d_{I} .
$$

It is worth mentioning that the rest of the equation expresses the demographic change. The second block of equations indicates that the number representing employment is equal to the induced labor demand by total production:

$$
-l x_{I}+\mathrm{em}=0 \text {. }
$$

Then,

$$
\mathrm{em}=l x_{I}
$$

The third block of equations shows that the labor supply consists of the number of employed and unemployed:

$$
\mathrm{em}+\mathrm{ue}=p
$$

From the block equation structure of this model, we conclude that it is possible to partition the matrix coefficients, and the vectors of activity level and inputs, to separate the economic and demographic characteristics of the system, as shown in Table 1.

\subsection{Model elaboration with urbanization}

Urbanization is defined as the process of population movement from rural areas to urban areas. Farmers are mainly engaged in agricultural production, and usually, want to migrate to cities to find better jobs and seek a better life. City dwellers who were previously farmers have become an important component of the labor force in factories and offices. At the same time, they enjoy the modern consumption life.

Dividing households into those in cities and those in villages, the input-output model for urbanization is constructed as an application of the rudimentary BateyMadden model in Eq. (6): 


$$
\left[\begin{array}{ccc}
I-A & -\dot{h}_{c}^{u} & -\dot{h}_{c}^{r} \\
-l \alpha & 1 & 0 \\
0 & 1 & 1
\end{array}\right]\left[\begin{array}{c}
x_{I} \\
u \\
r
\end{array}\right]=\left[\begin{array}{c}
d_{I} \\
0 \\
p
\end{array}\right],
$$

where $\dot{h}_{c}^{u}$ is a column vector of consumption coefficients, expressed as consumption per person, for an urban worker; $\dot{h}_{c}^{r}$, a column vector of consumption coefficients, expressed as consumption per person, for a rural worker; $l$, a row vector of urban employmentproduction (urban employment/gross output ratios) functions by industrial sector, and $\alpha$ is a scalar, the spatial friction coefficient, showing the level of difficulty during migration, such as distance and cultural differences. It takes a value from 0 to $1 . u$ is a scalar, the number of urban workers; $r$, a scalar, the number of rural workers, and $p$ is a scalar, the level of labor supply.

The first term of Eq. (6) is derived as follows:

$$
(I-A) x_{I}-\dot{h}_{c}^{u} u-\dot{h}_{c}^{r} r=d_{I} .
$$

Equation (7) shows that the undetermined variable, total output, is sought through inter-industrial relations and household consumption of both urban workers and rural workers under the constraints of other final demand, such as capital formation and net exports. The rest of Eq. (6) indicates the demographic changes that occurred in the process of urbanization:

$$
-l \alpha x_{I}+u=0 .
$$

Furthermore,

$$
u+r=p .
$$

Equation (9) shows that the national labor supply is composed of urban workers and rural workers, and urban workers are induced by urban employment opportunities, defined as the following equation transformed from Eq. (8):

$$
u=l \alpha x_{I} .
$$

Equation (10) indicates that the total output of the economy determines the urban employment opportunities and these new additional job opportunities are covered by migrants from rural areas by overcoming any obstacles to movement. To simplify, the urbanization process assumes that the extra demand of the total economy is fulfilled by rural-urban migration only, even though the movement of labor may differ by sector. For instance, migration from agricultural sector in rural areas to service sectors in urban areas might be easier than from rural agricultural sector to urban manufacturing sector. Nevertheless, the difficulty represented by $\alpha$ is assumed to be the same regardless of the sector.

The demographic change can be expressed by substituting Eq. (10) into Eq. (9). Then,

$$
l \alpha x_{I}+r=p .
$$

Equation (11) shows that the total labor supply in the country consists of urban workers, including the labor migration to cities from villages and the rest of the population left in the countryside. As discussed earlier, the model's assumption that labor demand 
induced only by total output of the whole country determines the extent of migration from rural to urban areas, means that the economic expansion has no influence on the rural employment opportunities. Although this assumption seems to be unrealistic, the spatial friction coefficient $\alpha$ can also be seen as a gravity or pull power that new increased job opportunity in rural areas created by the country's total output prevents people from going to cities. Thus, $\alpha$ parameter plays a vital role in determining the number of migrants from rural to urban areas.

\subsection{Multiplier of the model}

Let us again analyze Eq. (6), the application form of the Batey-Madden model. If the matrix is partitioned with the economic and demographic activity, then it can be converted to a simple form of the equation, as follows:

$$
\left[\begin{array}{ccc}
I-A & -\dot{h}_{c}^{u} & -\dot{h}_{c}^{r} \\
-l \alpha & 1 & 0 \\
0 & 1 & 1
\end{array}\right]=\left[\begin{array}{cc}
I-A & -H_{c} \\
-H_{l} & D
\end{array}\right],
$$

where $H_{c}=\left[\dot{h}_{c}^{u} \dot{h}_{c}^{r}\right], H_{l}=\left[\begin{array}{c}l \alpha \\ 0\end{array}\right], D=\left[\begin{array}{ll}1 & 0 \\ 1 & 1\end{array}\right]$. In addition, $x_{d}=\left[\begin{array}{l}u \\ r\end{array}\right]$ is defined as the number of urban and rural workers, $d_{d}=\left[\begin{array}{l}0 \\ p\end{array}\right]$ is the number of commuting workers from rural areas, ${ }^{4}$ which is assumed to be an imbalance and therefore, set at zero, and the amount of economically active population or total labor supply of the country. Equation (6) can then be rewritten as

$$
\left[\begin{array}{cc}
I-A & -H_{\mathrm{c}} \\
-H_{l} & D
\end{array}\right]\left[\begin{array}{l}
x_{I} \\
x_{d}
\end{array}\right]=\left[\begin{array}{l}
d_{I} \\
d_{d}
\end{array}\right]
$$

The inverse matrix of $\left[\begin{array}{cc}I-A & -H_{c} \\ -H_{l} & D\end{array}\right]$ is defined as $\left[\begin{array}{cc}L^{11} & L^{12} \\ L^{21} & L^{22}\end{array}\right]$, and then, Eq. (13) is solved for unknown variables, that is, the total output of industry, and the number of urban and rural workers, by using the abovementioned inverse $L$ matrix:

$$
\left[\begin{array}{l}
x_{I} \\
x_{d}
\end{array}\right]=\left[\begin{array}{ll}
L^{11} & L^{12} \\
L^{21} & L^{22}
\end{array}\right]\left[\begin{array}{l}
d_{I} \\
d_{d}
\end{array}\right] .
$$

By further investigating the inverse matrix of the model, the analytical relationship embodied in Eq. (14) can be explored by analyzing each quadrant in detail. From Eq. (13), the following two equations can be obtained:

$$
\begin{aligned}
& (I-A) x_{I}-H_{c} x_{d}=d_{I}, \\
& -H_{l} x_{i}+D x_{d}=d_{d} .
\end{aligned}
$$

From Eq. (15),

\footnotetext{
${ }^{4}$ In reality, some workers living in the countryside commute to work in cities. However, in the model, for simplicity it is assumed that there are no commuting workers from rural areas to urban areas for jobs. This assumption means that rural workers work only in villages if they live in the countryside.
} 


$$
x_{I}=(I-A)^{-1} d_{I}+(I-A)^{-1} H_{c} x_{d} .
$$

Substituting (17) for (16),

$$
x_{d}=\left[D-H_{l}(I-A)^{-1} H_{c}\right]^{-1} H_{l}(I-A)^{-1} d_{I}+\left[D-H_{l}(I-A)^{-1} H_{c}\right]^{-1} d_{d} .
$$

Substituting (18) for (15),

$$
\begin{aligned}
x_{I}= & (I-A)^{-1}\left\{I+H_{c}\left[D-H_{l}(I-A)^{-1} H_{c}\right]^{-1} H_{l}(I-A)^{-1}\right\} d_{I} \\
& +(I-A)^{-1} H_{c}\left[D-H_{l}(I-A)^{-1} H_{c}\right]^{-1} d_{d} .
\end{aligned}
$$

This can be further simplified, where $B=(I-A)^{-1}, L^{22}=\left[D-H_{l} B H_{c}\right]^{-1}$, so that

$$
\left[\begin{array}{l}
x_{I} \\
x_{d}
\end{array}\right]=\left[\begin{array}{cc}
B\left(I+H_{c} L^{22} H_{l} B\right) & B H_{c} L^{22} \\
L^{22} H_{l} B & L^{22}
\end{array}\right]\left[\begin{array}{c}
d_{I} \\
d_{d}
\end{array}\right] .
$$

This is another expression of Eq. (14), enabling us to understand what this inverse matrix means. $L^{22}=\left[D-H_{l} B H_{c}\right]^{-1}$ in the model for urbanization, corresponding to the inter-relational income multiplier defined by Miyazawa, ${ }^{5}$ is expressed as Eq. (20) and plays a crucial role in this model. Different from the inter-relational income multiplier, the situation of labor market $D$ influences the model performance. In other words, the number of rural and urban workers determines the changes of the multiplier.

\subsubsection{Interpretation of $L^{22}$}

First, we investigate $L^{22}=\left[D-H_{l} B H_{c}\right]^{-1}$, which plays an important role in the implementation of this model.

As presented in matrix algebra (18) above,

$$
L^{22}=\left[D-H_{l} B H_{c}\right]^{-1}=\left\{\left[\begin{array}{ll}
1 & 0 \\
1 & 1
\end{array}\right]-\left[\begin{array}{c}
l \alpha \\
0
\end{array}\right] B\left[\dot{h}_{c}^{u} \dot{h}_{c}^{r}\right]\right\}^{-1} .
$$

This expression can be further simplified as

$$
L^{22}=\left[\begin{array}{cc}
1-l \alpha B \dot{h}_{c}^{u} & -l \alpha B \dot{h}_{c}^{r} \\
1 & 1
\end{array}\right]^{-1} .
$$

This yields

$$
L^{22}=\left[\begin{array}{ll}
L_{11}^{22} & L_{12}^{22} \\
L_{21}^{22} & L_{22}^{22}
\end{array}\right]=k\left[\begin{array}{cc}
1 & l \alpha B \dot{h}_{c}^{r} \\
-1 & 1-l \alpha B \dot{h}_{c}^{u}
\end{array}\right],
$$

where $k=1 /\left(1-l \alpha B \dot{h}_{c}^{u}+l \alpha B \dot{h}_{c}^{r}\right)$,

$$
L_{11}^{22}=\frac{1}{1-l \alpha B \dot{h}_{c}^{u}+l \alpha B \dot{h}_{c}^{r}}
$$




$$
\begin{aligned}
& L_{12}^{22}=\frac{l \alpha B \dot{h}_{c}^{r}}{1-l \alpha B \dot{h}_{c}^{u}+l \alpha B \dot{h}_{c}^{r}}, \\
& L_{21}^{22}=\frac{-1}{1-l \alpha B \dot{h}_{c}^{u}+l \alpha B \dot{h}_{c}^{r}}, \\
& L_{22}^{22}=\frac{1-l \alpha B \dot{h}_{c}^{u}}{1-l \alpha B \dot{h}_{c}^{u}+l \alpha B \dot{h}_{c}^{r}} .
\end{aligned}
$$

The element $L_{11}^{22}$ shown in Eq. (24), or $k=1 /\left(1-l \alpha B \dot{h}_{c}^{u}+l \alpha B \dot{h}_{c}^{r}\right)$, can be interpreted as a multisectoral urban employment multiplier, which means the induced employment generated by the changes in per capita consumption of both urban and rural residents through the input-output relation of industries. This is analogous to the Keynesian multiplier, as mentioned in Batey (2018). This may indicate the effect on the urban employment level of an exogenous unit with an increase in urban employment, which denotes the unit increase in the number of workers outside the country (it is set to zero in this model; see the element of $d_{I}$ ). In this model, all job opportunities are assumed to take place only in urban areas so that Eq. (24) shows urban employment generated by a unit increase of labor force, based on the assumption that workers have not migrated from overseas. By contrast, Eq. (26) represents the mirror image of this effect on rural employment in the region.

Since $l \alpha B \dot{h}_{c}^{u}$ and $l \alpha B \dot{h}_{c}^{r}$ are the direct and indirect effects on the employment of the consumption of an urban or rural worker, respectively, the two remaining elements $L_{12}^{22}$ and $L_{22}^{22}$ represent the effects on urban and rural workers, respectively, with respect to a unit increase in the size of labor supply or economically active population. An increase in labor supply must be allocated to either the urban or rural population, and therefore, can be interpreted as the probabilities of spatial labor allocation, as the sum of $L_{12}^{22}$ and $L_{22}^{22}$ is unity, according to Eqs. (25) and (27). Applying Batey's (2018) interpretation to this context, the probabilities can be interpreted as, in the former case, the probability of moving to cities for employment and, in the latter case, the probability of workers remained in rural areas, assuming that the other factors, particularly final demand, remain constant.

In summary, quadrant $L^{22}$ of the complete multiplier denotes the impact on the allocation of the urban and rural population based on the changes in labor supply or demographic factors. Hence, these multipliers can be called "urban and rural labor allocation multipliers," or more simply, "urbanization multipliers," because they show the direct effects of the movement of people into cities. This quadrant provides a basis for weighing the impacts due to changes in the elements of the spatial labor market between urban areas and rural areas. Therefore, our urbanization multiplier can be interpreted as in Table 2.

\subsubsection{Interpretation of $L^{21}=L^{22} H_{l} B$}

Let us move on to the lower-left side item of the multiplier in Eqs. (14) and (20). It is obvious that if the focus is on the impact caused by changes in economic activity, represented by $d_{d}$, and the labor supply remains unchanged and is represented as zero, then 
Table 2 Interpretation of urban and rural labor allocation multiplier ( $\left.L^{22}\right)$

\begin{tabular}{lll}
\hline & Column 1 (multiplier) & Column 2 (probability) \\
\hline Urban employment & Urban employment multiplier & The probability of urban employment \\
& $L_{11}^{22}$ & $L_{12}^{22}$ \\
Rural employment & Rural employment multiplier & The probability of rural employment \\
& $L_{21}^{22}$ & $L_{22}^{22}$ \\
\hline
\end{tabular}

the impact on urban employment can be estimated by the final demand from Eq. (25), as follows:

$$
x_{d}=L^{21} d_{I} .
$$

The $L^{21}$ quadrant of the inverse matrix in Eq. (28) contains information about the direct, indirect, and induced effects by a unit change in final demand. This quadrant is expressed in a manner similar to $L^{22}$ :

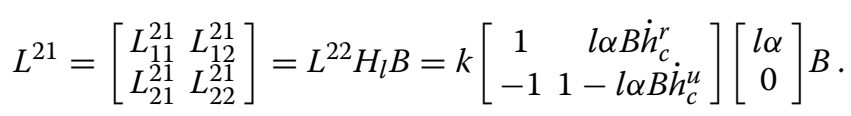

Each element of the submatrix $L^{21}$ is expressed as follows:

$$
\begin{aligned}
& L_{11}^{21}=\frac{l \alpha B}{1-l \alpha B \dot{h}_{c}^{u}+l \alpha B \dot{h}_{c}^{r}}, \\
& L_{21}^{21}=\frac{-l \alpha B}{1-l \alpha B \dot{h}_{c}^{u}+l \alpha B \dot{h}_{c}^{r}} .
\end{aligned}
$$

Here, the other elements of the submatrix are zero; that is, $L_{12}^{21}=L_{22}^{21}=0$. It is worth reporting that $L_{11}^{21}$ and $L_{21}^{21}$ are presented in vector form, unlike the elements of $L^{22}$, which are presented in scalar form. In the most straightforward case, in which only one type of urban worker is identified, the row vector $L_{11}^{21}$ denotes urban employment effects, while the second element $L_{21}^{21}$ indicates rural employment effects. As highlighted in the case of employment and unemployment by Batey (2018), since an increase in urban employment is matched by a corresponding decrease in rural employment, Eq. (31) merely repeats the elements of Eq. (30) with the signs reversed. Therefore, Eq. (31) is the mirror image of Eq. (30), and Eq. (30) can be interpreted as the number of urban employed, which is induced by a unit increase in the final demand of the economy.

\subsubsection{Interpretation of $L^{12}=B H_{C} L^{22}$}

Looking at the upper-right item of the inverse matrix in Eqs. (14) and (20), which can be described as follows, we assume that the industrial final demand equals zero:

$$
x_{I}=L^{12} d_{d}=B H_{c} L^{22} d_{d} .
$$

The $L^{12}$ quadrant of the inverse matrix in Eq. (32) shows interdependency between the economy and demography, giving us information about the direct, indirect, and induced effects when a unit change occurs in labor supply. This quadrant can be shown as follows, using $L^{22}$, the urbanization multiplier defined above: 
Table 3 Image of inverse matrix of extended input-output model for urbanization

\begin{tabular}{lll}
\hline & Industry & Labor allocation (multiplier, probability) \\
\hline Industry & $B\left(I+H_{c} L^{22} H_{1} B\right)$ & $B H_{c} L^{22}$ \\
& Output multiplier & Induced output by the changes in per capita consumption \\
Labor migration & $L^{22} H_{1} B$ & $L^{22}$ \\
& $\begin{array}{l}\text { Induced urban employment } \\
\text { and reduced rural employ- } \\
\text { ment }\end{array}$ & $\begin{array}{l}\text { Urban and rural labor allocation multiplier, urbanization } \\
\text { multiplier }\end{array}$ \\
& & \\
\hline
\end{tabular}

$$
L^{12}=B H_{c} L^{22}=B\left[\dot{h}_{c}^{u} \dot{h}_{c}^{r}\right]\left[\begin{array}{ll}
L_{11}^{22} & L_{12}^{22} \\
L_{21}^{22} & L_{22}^{22}
\end{array}\right]=\left[B\left(\dot{h}_{c}^{u} L_{11}^{22}+\dot{h}_{c}^{r} L_{21}^{22}\right) B\left(\dot{h}_{c}^{u} L_{12}^{22}+\dot{h}_{c}^{r} L_{22}^{22}\right)\right] .
$$

This is shown in two-column vectors by the industrial sector. The left one, $B\left(\dot{h}_{c}^{u} L_{11}^{22}+\dot{h}_{c}^{r} L_{21}^{22}\right)$, is the output multiplier multiplied by increased per capita consumption, which is induced by the urban employment multiplier, $L_{11}^{22}$, and reduced by the rural employment multiplier, $L_{21}^{22}$. In other words, the multiplier of the extent of the power that the urban industries have to attract workers from the countryside determines household consumption, and then, generates the production of goods and services to meet this increased consumption. Similarly, the right element of Eq. (33), that is, $B\left(\dot{h}_{c}^{u} L_{12}^{22}+\dot{h}_{c}^{r} L_{22}^{22}\right)$, also indicates the output produced to meet the expanded consumption of both urban and rural households, but they are directly affected by the possibility of total labor allocation to two areas, urban or rural. Both vectors are shown in monetary units.

\subsubsection{Interpretation of $L^{11}=B\left(I+H_{c} L^{22} H_{l} B\right)$}

The last quadrant to be explained is multiplier, $L^{11}$, which represents the production of output stimulated by final demand. This is composed of two parts, namely, the ordinary Leontief inverse, $B$, and another augmentation coefficient by the final demand stimulus, $B H_{c} L^{22} H_{l} B$. Starting from the right-hand side, $H_{l} B$ indicates that the initial output multiplier generates urban labor employment; then, $H_{c} L^{22} H_{l} B$ translates that into consumption expenditure per person through changes in the amount of labor allocation between urban and rural areas. Multiplying this by the Leontief inverse shows the output multiplier by the induced consumption.

The inverse matrix of the extended model for urbanization shown in Eq. (14) is summarized in Table 3.

Finally, we investigate Eqs. (14) and (20) from the aspect of impacts brought by endogenous factors, such as final demand and total supply of labor. In fact, this impact model can be interpreted in the same way as the conventional household endogenous model in relation to the total output, which has impacts on the whole economy. The first row of Eq. (14) is expressed as

$$
x_{I}=L^{11} d_{I}+L^{12} d_{d} .
$$

Equation (34) shows that the total output is the sum of the output induced by the final demand $\left(L^{11} d_{I}\right)$ and the output generated or intensified by the per capita consumption 
changes, which is caused by changes in labor supply. This implies that the output is increased due to a rise in final demand items, such as investment and exports, as well as growth in labor population.

The second row of Eq. (14), which is derived as follows, requires detailed explanation:

$$
x_{d}=L^{21} d_{I}+L^{22} d_{d} .
$$

The number of urban and rural workers, $x_{d}$, can be obtained by summing up the numbers induced by final demand, $L^{21} d_{I}$, and by demographic change, $L^{22} d_{d}$. The size of the urban labor force can be determined by the amount of final demand in the country because laborers are assumed to be employed in urban factories to meet the increased demand. In this model, these newly employed people are considered to have migrated from rural areas. Demographic change also has an impact on the determination of the number of urban and rural workers. The increased size of the total labor population in the country can be allocated to the rural or urban area through the urbanization multiplier, $L^{22}$. Therefore, Eq. (35) is of enormous importance in investigating the urbanization process.

\section{Empirical analysis and implications of the model}

\subsection{Target country, data, and methodology}

In the previous section, we develop an extended input-output model for urbanization and theoretically investigate the meaning of each multiplier between demography and economy. In this section, we test how the model works using real data. In particular, we observe how the demographic part of the submatrix, called the urbanization multiplier here, changes empirically.

We choose China for our empirical study, as it typifies the kind of region in which our model is likely to prove most meaningful and useful. Since 1978, when China's opening and reform policy started, major cities in the coastal area have expanded rapidly, mainly reflecting an increase of foreign investment. Despite the restrictions of the household registration system (hukou), massive labor force has flowed into cities. This movement has accelerated since the government started promoting urbanization and townization ${ }^{6}$ as an economic policy in 2014 to overcome the so-called "middle-income trap". Urbanization has increased the productivity of Chinese cities, and this is considered a decisive engine of economic growth (Griffiths and Schiavone 2016; Okamoto 2017). The growing urban population may have an important effect on the regional economy. At the same time, the urban area in China is faced with severe problems related to urbanization, such as environmental impact (e.g., Ala-Mantila et al. 2014; Li et al. 2015; Feng and Hubacek 2016) and the rapid construction of urban infrastructure (Okamoto 2019b). Therefore, a good understanding of the inter-relationship between demographic and economic change is vitally important for the formulation of strategic urban planning. Hence, examining the impact of Chinese urbanization, specifically, the inter-relational process between the economy and migration (e.g., how economic activity impacts migrants in

\footnotetext{
${ }^{6}$ The term "urbanization" in the Chinese context includes a wider range of concentration of people in cities and towns from rural areas. Thus, for precision, urbanization and townization are appropriate for a discussion on urbanization in China.
} 
cities and vice versa), is an appropriate example to clarify our model, which regards migration as a main feature of demographic change.

The data (labor accounts and input-output tables) are from the China Statistical Yearbook published by China's National Bureau of Statistics (NBS). The NBS has compiled the China input-output tables by survey-based data every 5 years since 1987 and has updated the tables every 5 years from 1990. This empirical study uses the 2002, 2007, and 2012 input-output tables, which are survey-based benchmark tables, and the 2005, 2010, and 2015 tables, which are updated from the nearest benchmark tables. They are all compiled and released by the NBS.

To clarify the function of the model, we proceed with the following three steps of analysis. First, we obtain an overall picture of the model by calculating the whole multiplier based on the latest data, which are the 2015 input-output table for China and the labor account for the same year, 2015. Second, we ascertain the model accuracy by predicting the total output and total labor in both urban and rural areas. At the same time, we discuss the friction of spatial labor movement from the countryside to cities. Third, we attempt to determine the inter-relationship between economic and demographic change. We investigate how the result would change in the case of both (1) changes in labor data with the fixed input-output data and (2) changes in input-output data with fixed labor data. The former shows to what extent labor migration affects the multipliers, and the latter offers insights into the impacts of economic structure on the model.

When it comes to model size, we highly aggregate the number of sectors into three sectors. The reason for doing so is that we mainly emphasize not labor movement between sectors, but the impact of migration as a representative feature of demographic change on the whole economy and, in turn, the impact of economic development on urbanization. We consider that this could best be achieved by an aggregated model of economic sectors in which the pattern of relationships between economic variables and demographic variables is made explicit. It is easy to grasp the demographic impact if economic variables (sectoral variables here) are reduced.

\subsection{Multipliers of the model}

First, we investigate the result of the model implementation by using the 2015 China input-output table ${ }^{7}$ and labor account for 2015. To calculate the multiplier, the spatial friction coefficient needs to be estimated. The coefficient is set to 1 here, meaning that job opportunities created in cities can be fulfilled immediately by migrant workers from the countryside. This is discussed in detail in the following subsection.

Table 4 shows the outcome calculated from the model for urbanization. Each part of the table corresponds to the inverse matrix shown in Table 3.

First, we consider the subpart of Table 4 (the upper-left), the matrix of industry by industry. Since the households are incorporated into the model, each cell of the multiplier is larger than the output multiplier of the conventional Leontief inverse, and the total of the column, which is seen as the total backward linkage effect indicating 2.560 for the primary sector, 4.255 for the secondary sector, and 3.307 for the tertiary

\footnotetext{
7 The data are provided as a format of the so-called import-competitive type. Each transaction includes imported goods and services. We plan to undertake this elimination work in future research.
} 
Table 4 Results of the model execution for 2015

\begin{tabular}{lcccll}
\hline & Primary & Secondary & Tertiary & Multiplier & Probability \\
\hline Primary & 1.215 & 0.208 & 0.106 & 6429 & 4275 \\
Secondary & 0.939 & 3.088 & 1.200 & 67,089 & 31,359 \\
Tertiary & 0.406 & 0.959 & 2.000 & 54,662 & 22,237 \\
Total & 2.560 & 4.255 & 3.307 & 128,180 & 57,871 \\
Urban employment & 3.18 & 6.87 & 8.94 & 1.280 & 0.119 \\
Rural employment & -3.18 & -6.87 & -8.94 & -1.280 & 0.881 \\
\hline
\end{tabular}

A unit of household consumption is in yuan and employment is measured in people

sector. This implies the extent to which industrial outputs are produced in order to satisfy an additional unit increase of final demand in each industry, in the same way that the conventional model does.

Next, the upper-right part of Table 4 shows the output generated by the increase in per capita consumption induced by a unit increase in demographic change. The increase in economically active population induces the total output of the industries to meet their increased consumption due to the changes in the composition of urban and rural workers. The total induced outputs, which are the sum of the column, are 128,180 yuan for the urban employment multiplier, which attracts people to employment in cities, and 57,871 yuan for the probability that a unit increase of population is allocated to urban or rural areas.

Third, we find the employment induced by final demand in the lower-left of Table 4 . In this model, it is assumed that employment is induced only in urban areas by the final demand of sectors and that this employment is obtained by job seekers who migrate from rural areas without any obstacles for movement, since the spatial friction coefficient is set to one. The number of employees in urban areas increases by 3.18 people in the primary sector, 6.87 people in the secondary sector, and 8.94 people in the tertiary sector. In addition, the rural areas reflect a decrease in the same number of people. Thus, approximately 19 people migrate from villages to cities with a unit increase ( 1 trillion yuan) in final demand.

Finally, the lower-right of Table 4 illustrates the information about demographic change, in particular, the process of urbanization in China, which is defined here as the urbanization multiplier. The urban employment multiplier is 1.280 , whereas the same negative figure can be shown as the rural employment multiplier. In the right column, this indicates the likelihood of spatial labor allocation, showing that the probability of taking a job in urban areas is $0.119(11.9 \%)$, and the probability of remaining in rural areas is $0.881(88.1 \%)$.

\subsection{Predictions of the model}

The model reliability depends on the accuracy of its forecast using the model compared with the real data. The multiplier obtained in the previous subsection can be used to predict the total output, and the number of urban and rural workers in a particular year based on the assumption that the multiplier is unchanged when the appropriate final demand and total labor supply are given in the model, as shown in 
Table 5 Predicted urban employment (million people). Source: author's calculation

\begin{tabular}{llll}
\hline & 2014 & 2015 & 2016 \\
\hline Prediction & 384 & 404 & 425 \\
Real & 393 & 404 & 414 \\
Discrepancy & $-2.4 \%$ & $0.0 \%$ & $2.6 \%$ \\
\hline
\end{tabular}

Eq. (14). If we obtain a better estimation for the number of urban employed, which is an important aspect of the urbanization process, the performance of the model can be regarded as reliable.

Table 5 illustrates the predicted urban employment in 2014 and 2016 when the final demand $^{8}$ and actual data of total labor supply in the corresponding year are inputted in the model.

The predicted urban employment in 2016 is slightly overestimated, and that in 2014 is modestly underestimated. This is partly because, in the model, it is assumed that job vacancies in cities are filled instantly by people in villages without considering migration obstacles. The discrepancy between the prediction and actual data is approximately $2.5 \%$, and this indicates that people in rural areas did not move to cities to obtain jobs owing to various factors, such as the emotional barriers of leaving their homes and moving costs between regions.

As Eq. (12) shows, these obstacles of movement can be treated as a spatial friction coefficient in our model, which may be around 0.975 based on this result. Thus, if we could obtain this appropriate coefficient, it would ensure model accuracy. Even though we cannot obtain the coefficient, which is assumed to be 1 , our model is still relevant for the analysis of urbanization, because there is only a small discrepancy.

In this study, our main purpose is to clarify how the model works. Hence, we proceed with the following analysis by making the spatial friction coefficient equal to 1 , because this estimation strongly depends on empirical analysis, which is far beyond our current topic.

\subsection{Changes in spatial labor account}

The labor account for the period 2000-2018 is used to analyze the urbanization process from the viewpoint of population movement from urban areas to rural areas. As Figs. 1, 2 , and 3 show, there was a tendency for laborers to migrate from rural areas to urban areas, along with a slight increase in total labor supply in China from 2008 to 2017.

First, the overall labor accounts are shown in Fig. 1. ${ }^{9}$ Figure 1 shows the labor force allocation of where employees work (without the unemployed population). Total population increased by 67 million people over the period, rising from 740 million workers in 2000 to 807 million workers in 2017, and the number of urban workers almost doubled from 232 million in 2000 to 425 million in 2017. On the contrary, there was a gradual decrease in the number of rural laborers from 489 million in 2000 and 352 million in

\footnotetext{
${ }^{8}$ Final demand in both years is estimated by extending the final demand in 2015 using the GDP growth rate.

9 Rural migrants are called Nongmingong in China; they work in cities without citizenship. However, they are considered as urban workers here. An analysis of rural migrants separately remains for future research.
} 

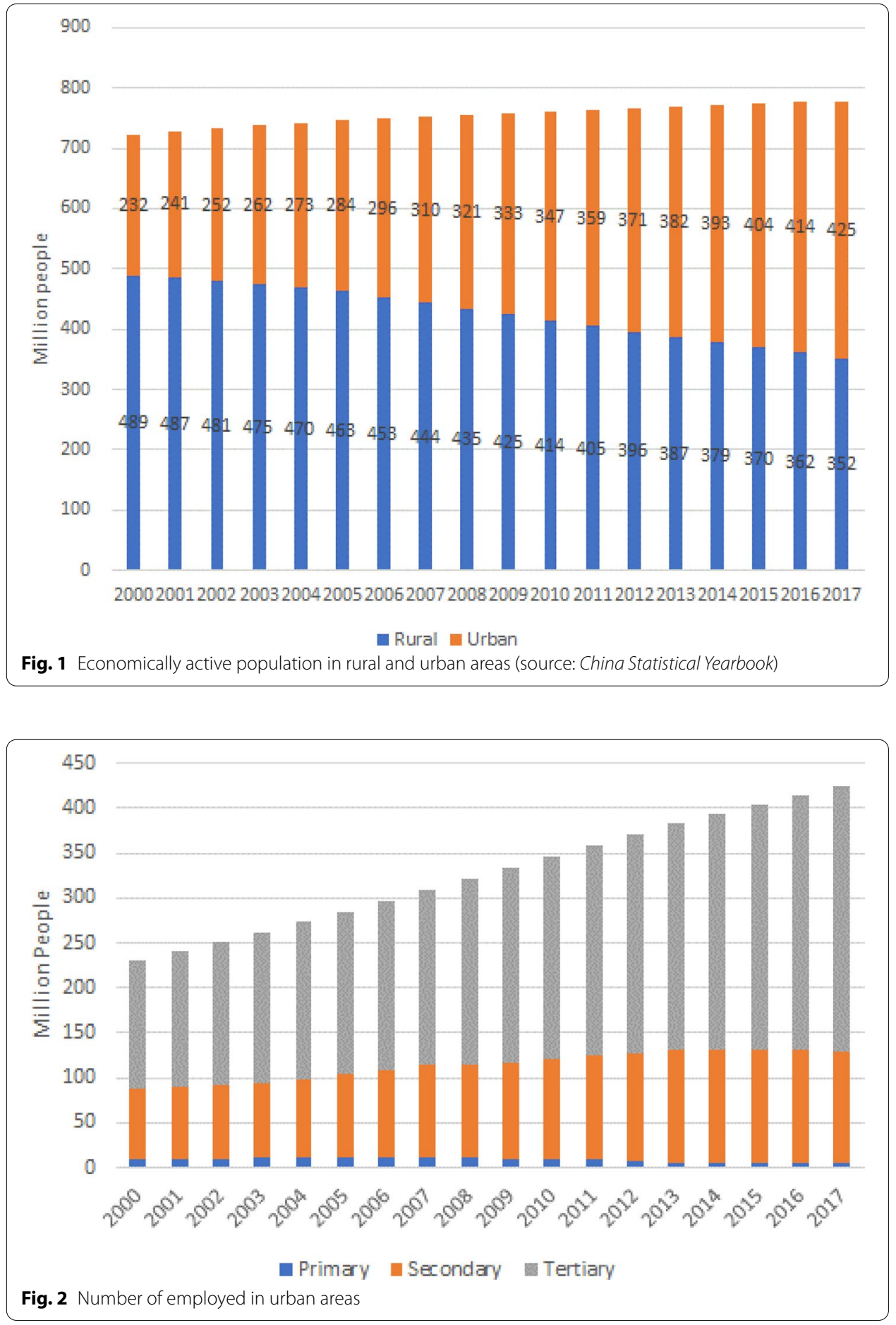

2017. The Chinese government started its new urbanization policy in 2012, after which a turning point is evident in 2015 , when urban workers became the main labor force among the total economically active population, and there were fewer rural workers than urban workers. It can be concluded that the development of the Chinese economy since then has been brought about by the urban labor force. 


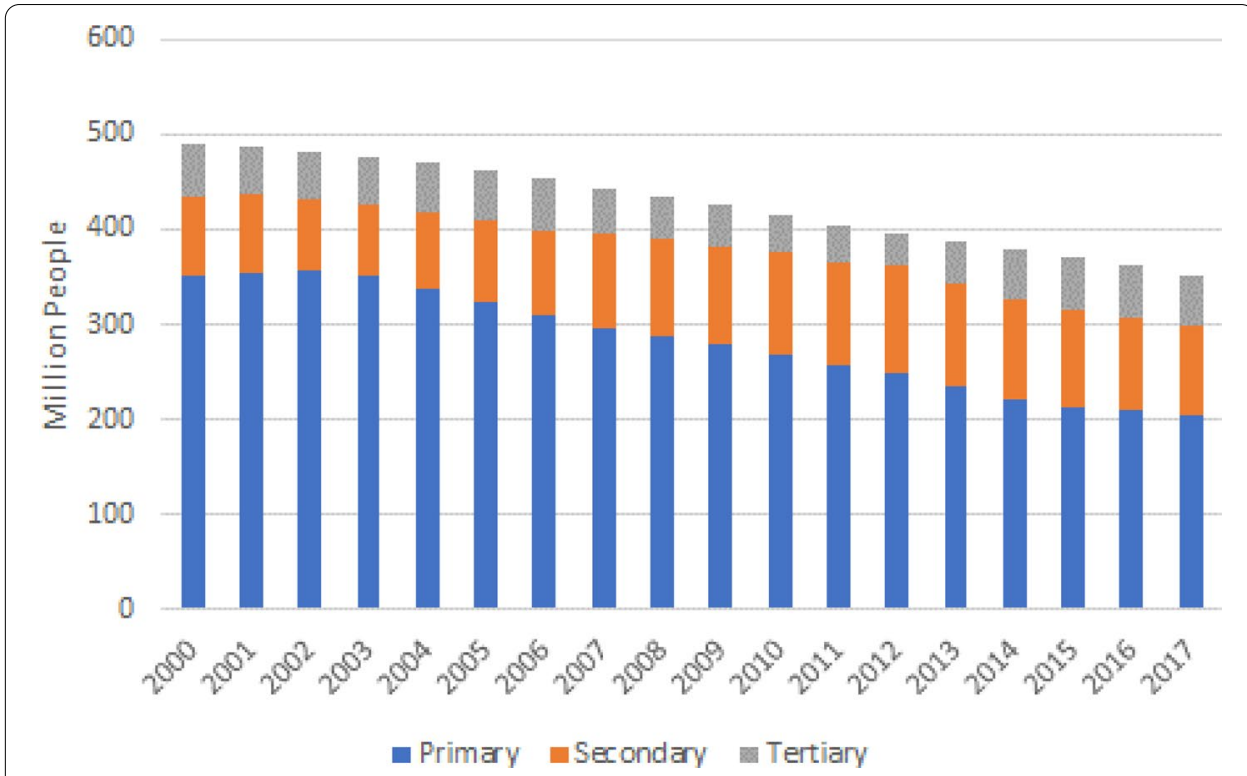

Fig. 3 Number of employed in rural areas (source: estimated from the China Statistical Yearbook)

Figure 2 indicates the number of employees by sector in cities ${ }^{10}$; it also describes which sector has absorbed the population in cities and pushed surplus workers from the countryside. It clearly reveals that the tertiary sector plays an important role in employment in urban areas. The number of people in the tertiary sector doubled from 143 million people in 2000 to 296 million people in 2017, accounting for $70 \%$ of total urban workers, whereas the number remained almost stable in manufacturing, and reduced gradually in the agricultural sector. On the contrary, the primary sector in the rural areas is the main source of labor supply to urban industries, as it reduced from 350 million people in 2000 to 203 million people in 2017. Meanwhile, the secondary sector rose from 84 million people in 2000, peaked at 113 million in 2012, and then gradually declined to 96 million people in 2017, showing that village or town enterprises play a dominant role in rural employment. For the primary sector, labor supply remained almost the same at around 50 million people over the period. In summary, almost the same number of people worked in the agricultural sector in villages as in the service sector in cities during these observed 18 years.

\subsection{Effects of changes in labor account}

To deepen our understanding of how the model works, the changes in each element of the multiplier in the model should be investigated by observing the changes of labor accounts from 2008 to 2017 with the 2015 input-output table remaining unchanged. In other words, we can find the impacts on the whole economy and demography rendered only by the changes in labor allocation between urban and rural areas, assuming that the economic structure is stable.

\footnotetext{
${ }^{10}$ We estimate the number of employees from the number of employed workers in urban units. Obviously, the number excludes workers in small private companies so that the sectoral employment in urban areas is calculated in accordance with the total amount of labor in urban areas, and the others are considered as workers in rural areas.
} 

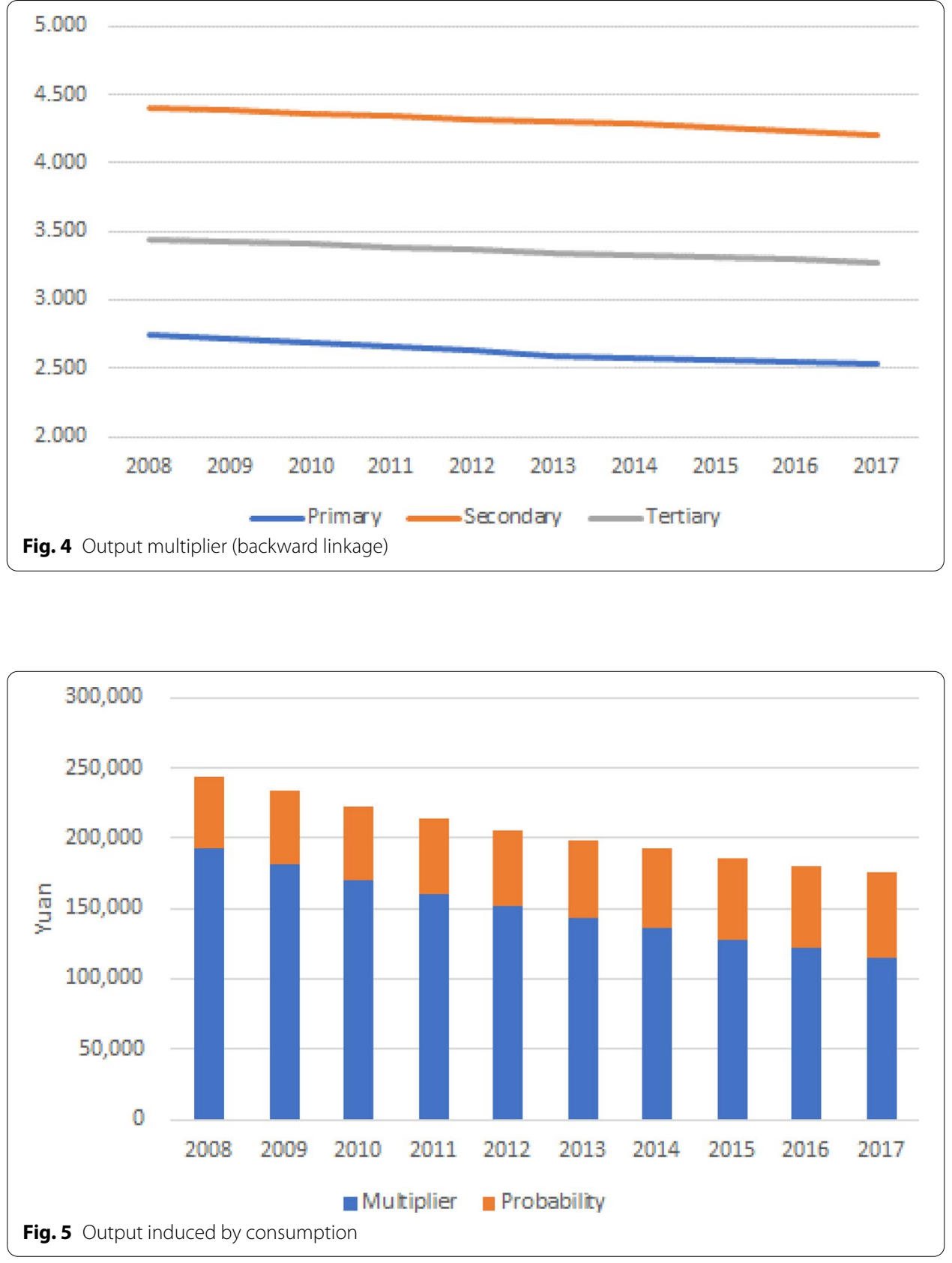

The results are shown in Figs. 4, 5, 6 and 7. Figure 4 indicates that with the constant of the input-output structure, the output multiplier or total sum of it, called backward linkages, was marginally decreasing even though the secondary sector had the strongest backward linkage among sectors. The movement of labor from sectors in rural areas to urban areas might have helped to reduce the backward linkages in the whole country. Reflecting this change in backward linkages, the output induced by total household consumption was also decreasing; in particular, the consumption induced by the urban employment multiplier was decreasing, but the consumption by urban and rural labor allocation probability experienced a slight rise, as shown in 

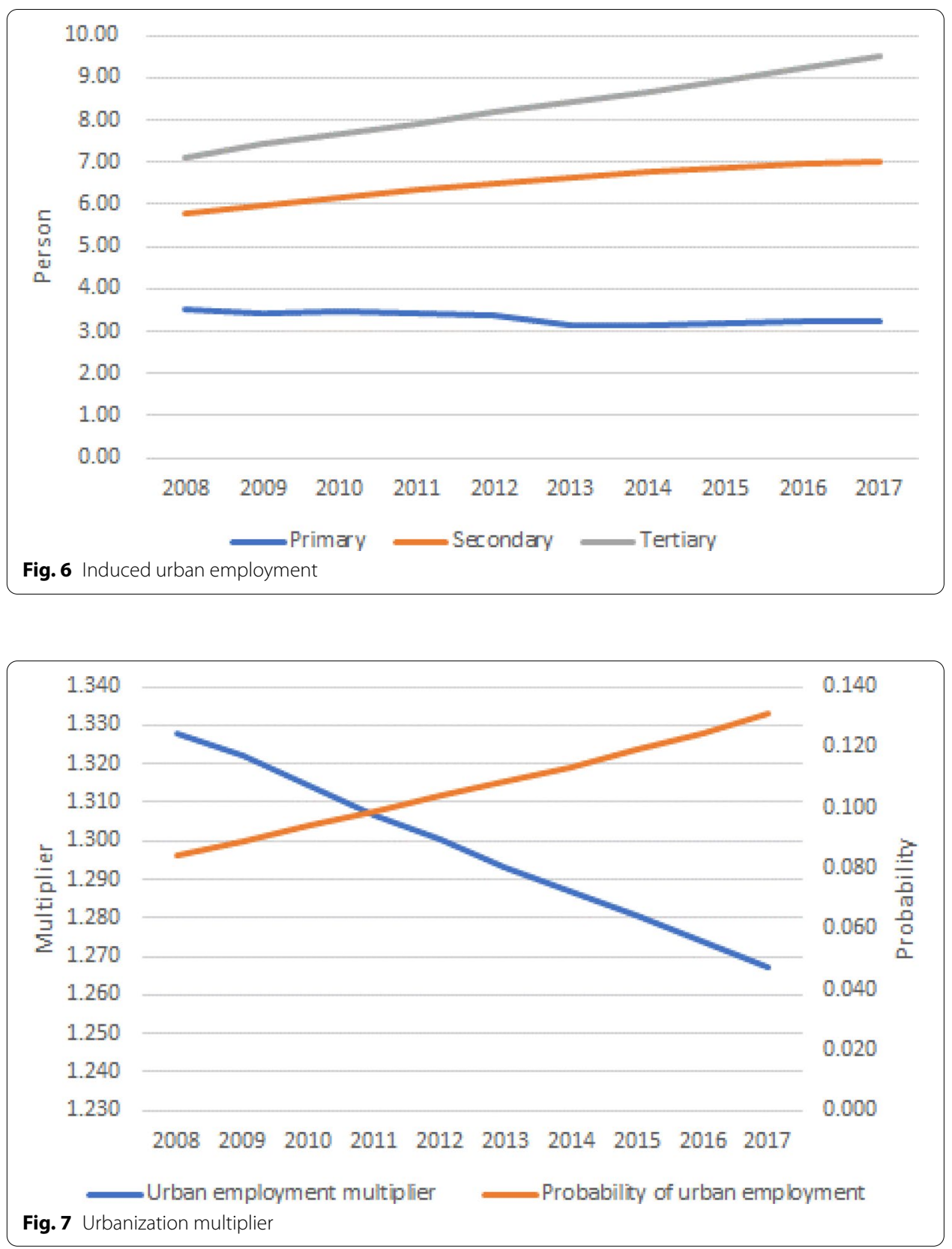

Fig. 5. This is partly because per capita consumption of the urban population was falling as the urban population was increasing.

Figures 6 and 7 show the changes in the lower side of the inverse matrix, specifically, urban employment (or movement to urban sectors) in Fig. 6 and the urbanization multiplier in Fig. 7. There was a constant increase in the number of people absorbed in the urban tertiary sector, while employment in the primary sector remained constant. Nevertheless, the urban employment multiplier was declining, whereas there was upward movement in the probability of urban employment. This result may indicate diminishing labor-absorbing power with the increase of the urban population, reflecting a higher probability of getting a job in cities as urbanization proceeds. 


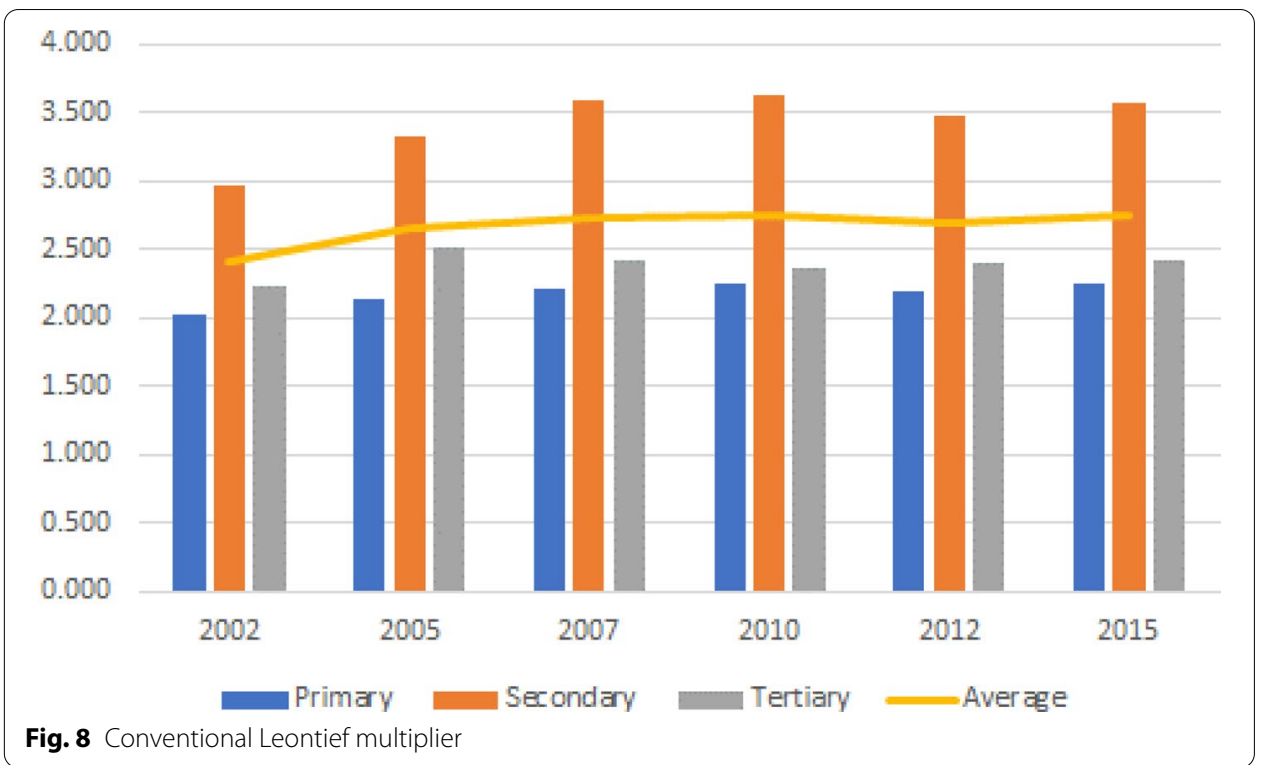

The findings are summarized as follows:

Under the condition that the input-output structure is the same as the population concentrates in cities,

1. the output multiplier and total production are decreasing; and

2. the employment multiplier in urban areas is also declining, although the probability of getting a job is increasing.

\subsection{Effects of changes in economic structure}

In contrast to the previous subsection, this subsection offers an insight into our model with a fixed labor account, and the input-output table varying for each year. It reveals how the economic structure affects the changes in the parameter of our model.

First, Fig. 8 shows the conventional Leontief or output multipliers from the inputoutput data of 2002 to 2015, at six consecutive points of time. There is an increasing trend in the average of backward linkages by sector, except in 2012, and the manufacturing sector has the biggest multiplier throughout the observed period. The multiplier of the service sector rose from 2002 to 2005, but it decreased to under 2.0 and remained almost unchanged. By and large, the intermediate transaction between sectors became denser and closer to each other, which is a common trend observed when countries are in a rapid development stage (Shishido et al. 2000).

Keeping this fundamental change in input-output multiplier in mind, we move on to analyze the inverse matrix of our extended input-output model for urbanization. We show the calculation results under the assumption that the input-output table is changing, but the labor account is fixed in 2015 so that we can observe the effects of the changes in the economic structure.

Figures 9 and 10 indicate the output multiplier, including demographic change, and the induced output by the consumption of urban and rural households. The multipliers 

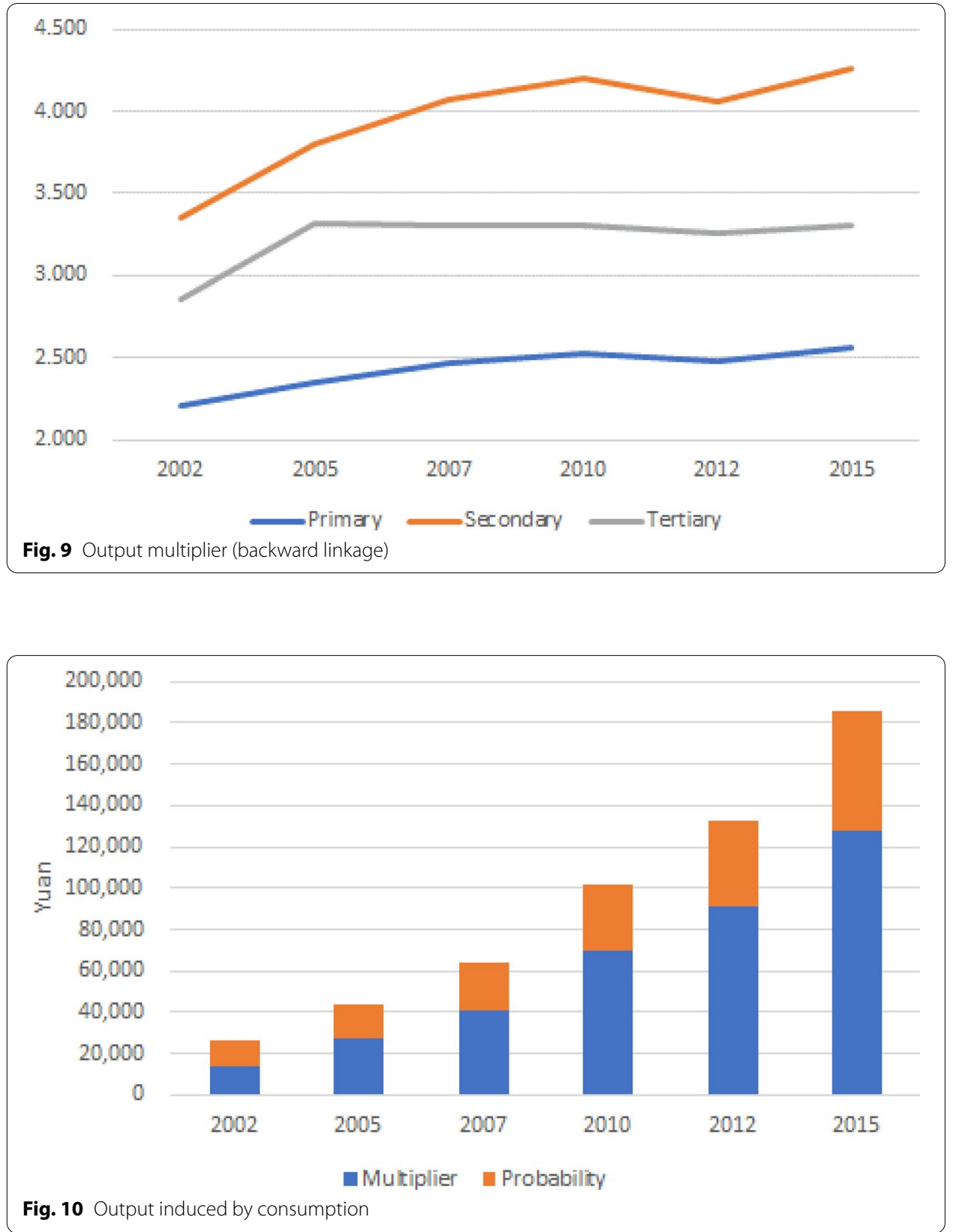

of the primary and secondary sectors rose from 2002 to 2010, dropped slightly in 2012, then increased to the highest level in 2015. The tertiary sector shows a similar trend; it remained at almost the same level from 2010 to 2015 after rising from 2002 to 2010 . For the output induced by consumption brought about by a unit increase in labor supply, the total output generated by spatial labor allocation dramatically increased from 26,474 yuan in 2003 to 186,051 yuan in 2015, and this increase was mostly from the change of the employment multiplier in urban areas. As the labor account was unchanged, the per capita consumption in both urban and rural areas increased, since the consumption figures in each input-output table increased significantly through economic development during the period. 

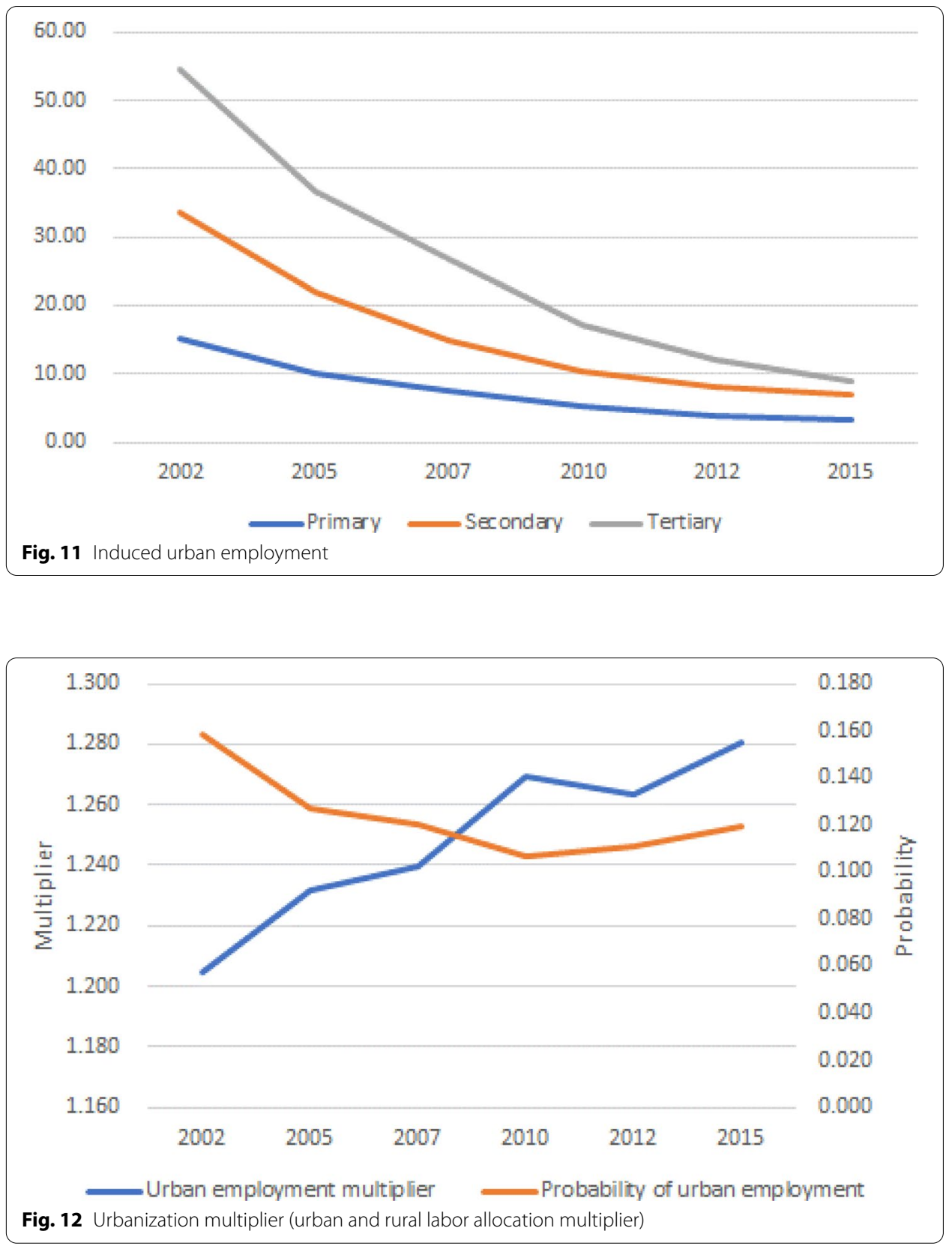

With rural workers, urban workers, and the total labor supply fixed in 2015, job opportunities in urban areas were on the decrease, as shown in Fig. 11. That seems to be counter to our intuition. However, the employment coefficient is obtained from the number of employed divided by total input in monetary units, and this was decreasing in the earlier period, resulting in the relatively smaller employment figures in the later period. As a result, fewer and fewer people were hired in each sector in cities.

Figure 12 illustrates the process of urbanization in China. It shows the urban employment multiplier and allocation of labor source to both urban and rural areas. There was a steady rise in the urban employment multiplier except for 2012. The output multiplier seems to have a significant influence on the urban employment 
multiplier, and this is quite understandable, simply because economic activities provide cities with employment opportunities.

On the contrary, the probability of urban labor allocation decreased from 2002 to 2010; thereafter, this trend reversed and increased until 2015.

We can summarize the findings as follows:

Under the condition that the labor account is unchanged, as the economy is developing,

1. the output multiplier and total production are increasing; and

2. there is an increasing trend for the employment multiplier in urban areas, although the probability of urban employment seems to be decreasing but unpredictable.

\section{Conclusion}

Significant contributions on demographic-economic modeling were made by Batey and his co-researchers mainly in the 1980s (Batey and Rose 1990). In this study, we explored an extension of the Batey-Madden model by incorporating the "urbanization process", which is associated with one of the facets of demographic change: labor migration from rural to urban areas in the input-output framework. Thus, the study also thoroughly analyzed the model structure, reinterpreted the inter-relationship between demographic-demographic changes, and as a result, proposed a new urbanization multiplier, which implies there is powerful population concentration in cities from the perspective of an employment multiplier in urban areas and labor allocation possibilities between both areas.

Our important findings are summarized as follows.

1. The Batey-Madden model has strong potential for use in the analysis of other demographic change, such as urbanization, considering the spatial friction of labor movement between rural and urban areas.

2. The urbanization multiplier, which is the inter-relationship of demographic change, shows a decrease of the employment multiplier and an increase of employment possibilities in cities as people move into urban areas under the condition that economic structure is unchanged. This can be interpreted as follows. Even though the labor demand in cities declines as an increasing number of rural workers move into cities, the newly increased population would be more likely to choose to work in cities. Therefore, as long as the economic structure remains the same, migration itself stimulates other migration from rural areas to urban areas.

3. As the economic structure changes, or as the Leontief multiplier increases over time, there is a constant rise in urban areas' employment multiplier, leading to the basic decreasing trend in the probability of urban employment, but this is not necessarily always true. Hence, on the assumption that the labor account is unchanged, the economic structure is certainly a crucial factor in the change of the urbanization multiplier, which implies the urbanization process. 
The framework of our extended input-output model for urbanization provides a useful basis for studying the relationship between urbanization and economic change. An important aspect of this change is the increase or decrease in the number of urban workers and rural workers, together with national labor supply. In fact, the model has been employed for analysis of the urbanization process of China preliminarily by using Chinese labor account data and input-output tables. The findings provide an insightful and new perspective of urbanization; in particular, economic structure determines the urbanization multiplier, indicating how many employment opportunities in urban area are created, and indicates the size of the population attracted from rural areas.

It is worth mentioning the limitations and challenges of the model, which can be addressed in future research. First, ours is a single-region model, not an inter-regional model between urban and rural areas. The technical coefficient in urban areas was implicitly assumed to be the same as that of the whole country, because the national input-output table was used in this model. In reality, the economic structures in urban areas are different from the national economic structure or rural areas' structures. The structure of urban economies is also likely to change fairly substantially as a result of inmigration. For example, urban areas are more industrialized, the manufacturing sector is more agglomerated, and there is production of a wider variety of goods and services than in rural areas, resulting in a different production structure in the economy.

Second, in this model, it is strongly assumed that farmers move instantly to cities if there are employment opportunities in urban areas, even though labor migration is widely considered as an adjustment process from both the demand side of job creation in cities and the supply side of people's living conditions in villages. Thus, the model is regarded as a so-called "demand pull-type" model. To overcome this problem, this study attempted to modify the model to reflect this reality as much as possible; we introduced the spatial friction coefficient, which fits the spatial adjustment process in the labor market. As discussed in Sect. 3.2, estimating this coefficient is left for future study.

Despite these limitations, this model has strong potential for further revelations concerning urbanization and hence, is suitable for more in-depth analysis. In this study, a simple model was used for a better understanding of the demographic parts of the model. To shed new light on the process of Chinese urbanization, the number of sectors needs to be expanded and variables are required to elaborate the model by reflecting the current situation in China (e.g., the existence of rural migrant workers in cities who are not treated as inhabitants of those cities) as well as by accumulating empirical research on wider aspects. There remains plenty of room for improvement of this model to clarify the urbanization process in China.

\section{Acknowledgements}

The first version of this paper was presented at the 27th International Input-Output Association Conference in Glasgow, UK. I thank the participants of the discussion whose comments helped to improve this revised version. I am also grateful to Editage (www.editage.jp) for English language editing.

Authors' contributions

The author read and approved the final manuscript.

Funding

The research is funded solely by the university at which the author is based.

Availability of data and materials

The datasets for the present study are available electronically and publicly. Data on labor account and input-output data are available from the website of the National Bureau of Statistics of China (NBS) as well as China Statistical Yearbook. 


\section{Declarations}

Competing interests

The author declares no competing interests.

Received: 2 March 2020 Revised: 23 February 2021 Accepted: 12 March 2021

Published online: 22 March 2021

\section{References}

Ala-Mantila S, Heinonen J, Junnila S (2014) Relationship between urbanization, direct and indirect greenhouse gas emissions, and expenditures: a multivariate analysis. Ecol Econ 104:129-139

Batey PWJ (1985) Input-output models for regional demographic-economic analysis: some structural comparisons. Environ Plan A 17(1):73-99

Batey PWJ (2018) What can demographic-economic modelling tell us about the consequences of regional decline? Int Reg Sci Rev 41(2):256-281

Batey PWJ, Madden M (1981) Demographic-economic forecasting within an activity-commodity framework: some theoretical considerations and empirical results. Environ Plan A 13(9):1067-1083

Batey PWJ, Madden M (1988) The treatment of migration in an extended input-output modelling framework. Ricerche Econ 42(2):344-366

Batey PWJ, Madden M (1999a) Interrelational employment multipliers in an extended input-output modeling framework. In: Hewings GJD, Sonis M, Madden M, Kimura Y (eds) Understanding and interpreting economic structure. Springer, Heidelberg, pp 73-89

Batey PWJ, Madden M (1999b) The employment impact of demographic change: a regional analysis. Pap Reg Sci 78(1):69-87

Batey PWJ, Rose AZ (1990) Extended input-output models: progress and potential. Int Reg Sci Rev 13(1-2):27-49 Batey PWJ, Weeks MJ (1987) An extended input-output model incorporating employed, unemployed, and in-migrant households. Pap Reg Sci 62(1):93-115

Batey PWJ, Weeks MJ (1989) The effects of household disaggregation in extended input-output models. In: Miller RE Polenske KR, Rose AZ (eds) Frontiers of input-output analysis. Oxford University Press, New York, pp 119-133

Batey PWJ, Madden M, Weeks MJ (1987) Household income and expenditure in extended input-output models: a comparative theoretical and empirical analysis. J Reg Sci 27(3):341-356

Feng K, Hubacek K (2016) Carbon implications of China's urbanization. Energy Ecol Environ 1(1):39-44

Griffiths M, Schiavone M (2016) China's new urbanisation plan 2014-20. China Rep 52(2):73-91

Hynes M, Jackson RW (1988) Demographics in demographic-economic models: a note on the basic activity-commodity framework. Environ Plan A 20(11):1531-1536

Li Y, Zhao R, Liu T, Zhao J (2015) Does urbanization lead to more direct and indirect household carbon dioxide emissions? Evidence from China during 1996-2012. J Clean Prod 102(1):103-114

Madden M (1988) Demographics in demographic-economic models: notes on two activity-commodity frameworks. Environ Plan A 20(11):1537-1542

Madden M, Batey PJW (1980) Achieving consistency in demographic economic forecasting. Pap Reg Sci Assoc 44:91-106

Miernyk WH, Bonner ER, Chapman JH, Shellhammer K (1967) Impact of the space program on a local economy: an input-output analysis. West Virginia University Library, Morgantown

Miller RE, Blair PD (2009) Input-output analysis_foundations and extensions, 2nd edn. Cambridge University Press, New York

Miyazawa K (1976) Input-output analysis and the structure of income distribution. Springer, Heidelberg

Okamoto N (2017) What matters in the urbanization of China? Northeast Asian Econ Rev 5(2):1-13. https://www.erina.or. jp/en/wp-content/uploads/2018/05/naer52-1_tssc.pdf

Okamoto N (2019a) Explanatory review on extended input-output model for demography. Keizaigaku Ronsan (J Econ) $60(1): 41-56$

Okamoto N (2019b) Spatial and institutional urbanisation in China. Asia-Pac J Reg Sci 3(3):863-886. https://doi.org/10. 1007/s41685-019-00113-y

Shishido S, Nobukuni M, Kawamura K, Akita T, Furukawa S (2000) An international comparison of Leontief input-output coefficients and its application to structural growth patterns. Econ Syst Res 12(1):45-64

\section{Publisher's Note}

Springer Nature remains neutral with regard to jurisdictional claims in published maps and institutional affiliations. 